\title{
Competitive Figure Skating Injuries
}

\author{
Joseph D. Fortin, DO, and Diana Roberts, PT, ATC
}

The nature, type and frequency of injuries occurring at a national figure skating competition were examined. Data was compiled from the medical history form of all 208 participants and the on-site evaluations of the 55 skaters who presented for treatment.

Twenty-six percent of all the skaters were injured during the competition. Senior skat-

Tenley Albright, MD, who was the 1956 Olympic Gold Medalist in figure skating, provided a compelling description of the rigors of competitive figure skating when she described the attributes of a good skater as one who embodies "the balance of a tightrope walker, the endurance of a marathon runner, the aggressiveness of a football player, the agility of a wrestler, the nerves of a golfer, the flexibility of a gymnast, and the grace of a ballet dancer"(1).

The following factors substantiate a need for the systematic evaluation of figure skating injuries:

1. Most competitive figure skaters begin training when they are physically immature $(2,3)$.

2. Competitive skaters train on the ice for three to six hours a day, five to seven days a week $(2,3)$.

3. Trends toward off-ice training, involving such activities as weight training, dance, and aerobic activities, are increasing the hours a skater trains $(2,3)$.

4. The sport has become increasingly athletically demanding. In order to achieve top scores, single skaters must perform more double, triple and even quadruple jumps; pair skaters must execute more lifts and throws (12).

From Spine Technology and Rehabilitation, and Indiana University School of Medicine, Fort Wayne, IN. Address Correspondence: Joseph D. Fortin, DO, Spine Technology and Rehabilitation, 7230 Engle Road, Suite 210, Fort Wayne, IN 46804. Email: fortin@pol.net

Funding: There was no external funding in preparation of this manuscript. ers accounted for more injuries than their junior counterparts. Pairs skaters appeared to be more susceptible to injury, incurring significantly more injuries than singles or dance skaters. As in other reports, injuries to the lower extremities predominated. Low back injury comprised $14.6 \%$ of all injuries. Thirty-five (64\%) of the 55 injuries were exacerbations of

5. Perhaps no other sport places the same diversity of forces on such a narrow base of support.

6. Correlations between figure skating injuries and the type of skating (singles, pairs, or dance), level of competitive involvement, and anthropometric variables are not well established. Few studies have been conducted, and the reported studies use conflicting methods of data collection, and some do not include physical examination data (26).

7. The significant rate of injury and the severity of injury (in terms of missed training days) to figure skaters suggests a need to evaluate predisposing factors and methods of rehabilitation(2-6).

This investigation examines the nature, type and frequency of injuries incurred by the 208 participants in a national figure skating competition.

\section{Methods}

Each of the athletes qualified for this national event by participating in one of nine regional events and subsequently, one of three sectional events, while meeting qualification standards of the United States Figure Skating Association. The subjects of this study were the 208 athletes who participated in a national figure skating competition. There were 90 singles, 60 pairs and 58 dance skaters. Each type of figure skating had representative participants of skill levels divided according to United States Figure Skating Asso- a pre-existing injury and twenty (36\%) were new ones.

Most competitive figure skating injuries are of the overuse type, suggesting a need to evaluate predisposing factors and methods of rehabilitation.

Key Words: Figure skating, low back injury, dancer, ballet

ciation (USFSA) test marks: novice, junior, and senior singles skaters; junior and senior pair skaters; and junior and senior dance skaters.

A standard medical history form was completed by each skater prior to the competition. Information regarding age, type of skater and the nature and regions of previous injury were obtained from the medical history form. A significant injury was defined as one which precluded training or impaired performance. Information regarding the experience level of each skater and their placements in previous competitions was obtained from the event program. Individual on-site evaluation and treatment forms were completed to collect information on the nature and type of injuries presenting at the time of competition.

The health care team consisted of 14 physicians, 7 physical therapists, and 22 athletic trainers rotating to provide full coverage at three sites. Depending on the severity of the injury, athletes were initially evaluated by a therapist and an athletic trainer. A diagnosis and a treatment plan was then confirmed by a physician. No medical records were available, and in many cases, no x-rays or other diagnostic studies were conducted. In most instances a presumptive diagnosis was made on the basis of clinical observation only. Physical examination parameters included anatomical alignment, stability, flexibility, and strength assessment as indicated. Equipment was likewise inspected. 
Competition accounted for only 65 of the total 268 skating hours. In general, all skaters shared equal ice time and no attempt was made to determine the rate of injury in each event (i.e., injuries per athlete hour). Since most injuries were of the overuse type the skater was unable to precisely identify the time of insidious onset. Injuries, therefore, were not separated into those occurring on the practice ice versus those occurring during actual competition, although there were no acute injuries noted during competition.

\section{RESULTS}

\section{Medical History Forms}

As shown in Table 1, skaters ranged from 10 to 30 years of age, and in general, skill levels increased with age, senior skaters being older than their juniors or novice counterparts. Single skaters tended to be younger than comparable skilled competitors in the pairs or dance events. The average age difference between senior male singles skaters and senior pair males was four years, while junior singles males and juniors pair males differed by 1.1 years. The female skaters were notably younger than their male counterparts
Table 1. The number, average age and range of ages of skaters according to event.

\begin{tabular}{|l|c|c|c|}
\hline & NO. & AVERAGE AGE & RANGE OF AGES \\
\hline SM - Senior Males & 18 & 19.2 & $(15-23)$ \\
\hline JM - Junior Males & 15 & 17.1 & $(15-20)$ \\
\hline NM - Novice Males & 12 & 15.4 & $(13-17)$ \\
\hline SL - Senior Ladies & 20 & 17.3 & $(15-19)$ \\
\hline JL - Junior Ladies & 13 & 15.2 & $(11-14)$ \\
\hline NL - Novice Ladies & 12 & 13.0 & $(18-30)$ \\
\hline SPM - Senior Pair Males & 18 & 23.2 & $(15-28)$ \\
\hline SPL - Senior Pair Ladies & 18 & 18.4 & $(14-23)$ \\
\hline JPM - Junior Pair Males & 12 & 18.2 & $(10-18)$ \\
\hline JPL - Junior Pair Ladies & 12 & 14.4 & $(21-27)$ \\
\hline SDM - Senior Dance Males & 15 & 23.2 & $(17-24)$ \\
\hline SDL - Senior Dance Ladies & 15 & 20.2 & $(16-24)$ \\
\hline JDM - Junior Dance Males & 14 & 19.7 & 17.7 \\
\hline JDL - Junior Dance Ladies & 14 & & $(15-23)$ \\
\hline
\end{tabular}

in each division. This difference was most pronounced in the pairs division, with a 4.8 year difference in the average age of the seniors and a 3.8 year difference in the juniors.
Table 2 displays the injuries reported on the medical history forms (prior to competition) with regard to the event and site of injury. Pairs skaters reported the most injuries at 1.83 injuries per

Table 2. Injuries reported on the Medical History Forms according to the event and site of injury

\begin{tabular}{|c|c|c|c|c|c|c|c|c|c|c|c|}
\hline SITE & HEAD & NECK & SHLD & HIP & KNEE & LEG & ANKLE & FOOT & BACK & TOTAL & \multirow{2}{*}{$\begin{array}{l}\text { Injuries Per } \\
\text { Participant }\end{array}$} \\
\hline Event: & & & & & & & & & & & \\
\hline SM & 2 & 1 & 1 & & 5 & 4 & 10 & & 5 & 28 & \multirow{6}{*}{1.32} \\
\hline JM & 1 & & 1 & & 6 & 2 & 8 & & 3 & 21 & \\
\hline NM & 1 & 1 & & & 5 & 1 & 2 & 1 & 4 & 15 & \\
\hline SL & 2 & 1 & & 4 & 6 & 8 & 10 & & 7 & 38 & \\
\hline $\mathrm{JL}$ & & & & & & 2 & 3 & & 2 & 7 & \\
\hline NL & & & 3 & & & 1 & 5 & & 1 & 10 & \\
\hline SPM & 4 & 2 & 7 & 3 & 3 & 2 & 7 & 2 & 4 & 34 & \multirow{4}{*}{1.83} \\
\hline SPL & 4 & & 1 & 3 & 6 & 4 & 8 & & 4 & 30 & \\
\hline JPM & 2 & & 2 & 1 & 2 & 1 & 5 & 1 & 4 & 18 & \\
\hline JPL & 4 & & 1 & 2 & 6 & 4 & 8 & & 3 & 28 & \\
\hline SDM & 3 & & & 2 & 3 & 1 & 2 & & 2 & 13 & \multirow{4}{*}{0.97} \\
\hline SDL & 2 & 1 & 2 & 1 & 3 & 1 & 5 & & 3 & 18 & \\
\hline JDM & & & 1 & 2 & 3 & 1 & 5 & & 1 & 13 & \\
\hline JDL & 3 & & & 1 & 5 & 1 & 1 & & 1 & 12 & \\
\hline Total Injuries & 28 & 6 & 19 & 19 & 53 & 33 & 79 & 4 & 44 & 285 & \\
\hline$\%$ of Total & 9.8 & 2.1 & 6.7 & 6.7 & 18.6 & 11.6 & 27.7 & 1.4 & 15.4 & & \\
\hline
\end{tabular}


participant (i.e., 110 injuries to 60 athletes), followed by singles skaters at 1.32 injuries per participant, and dance skaters at 0.97 . The number one area of injury was the ankle, accounting for 79 of 285 , or $27.7 \%$ of the total reported injuries. Second was the knee $(18.6 \%)$, and third, the lower back (15.4\%). Except for hip and knee injuries, lower extremity injuries were distributed fairly evenly among the events. All of the hip injuries were incurred by pairs and dance skaters, with the exception of the four hip injuries reported by the senior women. Head in- juries accounted for an alarming 28 of the $285(9.8 \%)$ injuries reported. Most of these were contusions and lacerations, but six were concussions; two each by senior pair females and males, and two by senior male single skaters. Pairs skaters incurred $50 \%$ or 14 of the injuries to the head, followed by dance skaters ( 8 or $29 \%$ ) and singles skaters (6 or $21 \%$ ). All of these injuries occurred in practice, while the athletes were learning new skills or maneuvers, as opposed to during the competition (when the skills hopefully had been attained).
Injury Evaluation and Treatment Forms

Table 3 shows the injuries which presented for evaluation and treatment at the time of competition analyzed with respect to event and the site of injury. Pairs skaters again accounted for the most injuries per participant (19) injuries in 60 skaters, or 0.32 injuries per participant), followed by singles skaters $(0.29)$, and dance skaters (0.17). In general, the type of injuries that were first-time presentations versus the pre-existing ones did not differ except for the cuts and contusions which all occurred at the competition and the low

Table 3. On-site injuries according to the event and the site of injury.

\begin{tabular}{|c|c|c|c|c|c|c|c|c|c|c|c|c|c|c|}
\hline SITE & NECK & SHLD & HIP & KNEE & LEG & ANKLE & FOOT & BACK & RIBS & WRIST & HAND & ELBOW & TOTAL & 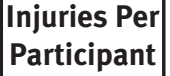 \\
\hline Event: & & & & & & & & & & & & & & \\
\hline SM & & & 2 & & 2 & & & 3 & & & & & 7 & \multirow{6}{*}{0.29} \\
\hline JM & & & & 1 & & & & & & 2 & & & 3 & \\
\hline NM & & & 1 & 1 & & & 2 & 1 & & & & & 5 & \\
\hline SL & & & 1 & 2 & 3 & 1 & & & & & & & 7 & \\
\hline JL & & 1 & & & & & & & & & & & 1 & \\
\hline NL & & & 1 & & 1 & & & 1 & & & & & 3 & \\
\hline SPM & 1 & 2 & & 1 & & & & & & & 1 & & 5 & \multirow{4}{*}{0.32} \\
\hline SPL & 1 & 1 & 2 & 1 & 2 & & & 2 & & & 1 & & 10 & \\
\hline JPM & & 1 & & 2 & & & & & & & & & 3 & \\
\hline JPL & & & & & & & & & & & & 1 & 1 & \\
\hline SDM & & & 1 & & & & & & & & & & 1 & \multirow{4}{*}{0.17} \\
\hline SDL & & 2 & & 2 & & & & & & 1 & & & 5 & \\
\hline JDM & & & & & & & & 1 & & & & & 1 & \\
\hline JDL & & & & & 1 & & 1 & & & & & 1 & 3 & \\
\hline $\begin{array}{c}\text { Total } \\
\text { Injuries }\end{array}$ & 2 & 7 & 8 & 10 & 9 & 1 & 3 & 8 & 0 & 3 & 2 & 2 & 55 & \\
\hline $\begin{array}{l}\% \text { of } \\
\text { Total }\end{array}$ & 3.6 & 12.7 & 14.6 & 18.2 & 16.3 & 1.8 & 5.5 & 14.6 & 0.0 & 5.5 & 3.6 & 3.6 & & \\
\hline
\end{tabular}


Table 4. The type of injuries that occurred in each event

\begin{tabular}{|c|c|c|c|c|c|c|c|c|c|c|c|c|c|c|c|c|}
\hline & SM & JM & NM & SL & JL & NL & SPM & SPL & JPM & JPL & SDM & SDL & JDM & JDL & TOTAL & $\%$ \\
\hline Muscle $^{a}$ & & 1 & & 1 & 1 & & & & & & & 2 & & 1 & 6 & 10.9 \\
\hline Ligament $^{b}$ & 2 & 1 & 1 & & & 1 & 1 & 2 & 2 & & & & 1 & & 11 & 20.0 \\
\hline Tendon $^{c}$ & 3 & 1 & 2 & 4 & & 1 & 2 & 3 & 1 & 1 & & & & 1 & 19 & 34.7 \\
\hline $\begin{array}{l}\text { Bursa Nerve } \\
\text { (HNP) }\end{array}$ & 1 & & & 1 & & & & & & & & & & & $\begin{array}{l}1 \\
1\end{array}$ & $\begin{array}{l}1.8 \\
1.8\end{array}$ \\
\hline Meniscus & & & & & & & & 1 & & & & 1 & & & 2 & 3.6 \\
\hline Contusion & & & & 1 & & 1 & 1 & 1 & & & & 1 & & 1 & 6 & 10.9 \\
\hline Fracture & & & 1 & & & & & 1 & & & & & & & 2 & 3.6 \\
\hline Stitches $^{d}$ & 1 & & 1 & & & & 1 & 2 & & & 1 & 1 & & & 7 & 12.7 \\
\hline Total & 7 & 3 & 5 & 7 & 1 & 3 & 5 & 10 & 3 & 1 & 1 & 5 & 1 & 3 & 55 & \\
\hline & \multicolumn{6}{|c|}{26} & \multicolumn{4}{|c|}{19} & \multicolumn{4}{|c|}{10} & & \\
\hline
\end{tabular}

back injuries which were all pre-existing (with the exception of a lumbar compression fracture). The leading injury site was the knee $(18.2 \%)$ and leg injuries were the second major cause of injuries (16.3\%). Low back and hip injuries each accounted for $14.6 \%$ of the total, followed by shoulder injuries (12.7\%). Twenty of the 55 injuries or $36 \%$ were new ones (occurring at the time of competition) while 35 or $64 \%$ were exacerbations of a pre-existing condition..

Pairs skaters suffered 4 of 7 or $57 \%$ of the shoulder injuries. Senior dance women had two shoulder injuries and one junior singles lady had a shoulder injury. Shoulder injuries included supraspinatus tendinosis, biceps tendinosis, and trapezius strains. There were two elbow contusions, two hand lacerations, and three wrist sprains due to falls. A variety of lower extremity injuries presented, including

Table 5. The comparison of medical history reports to on-site injury evaluations

\begin{tabular}{|l|l|}
\hline $\begin{array}{l}\text { Medical History Form Data } \\
\text { (285 Injuries) }\end{array}$ & $\begin{array}{l}\text { Injury Evaluation Form Data } \\
\text { (55 Injuries) }\end{array}$ \\
\hline 1. Ankle (27.7\%) leading area injured & 1. Knee (18.2\%) \\
\hline 2. Knee (18.6\%) & 2. Leg (16.3\%) \\
\hline 3. Low Back (15.4\%) & 3. Low Back (14.6\%) \\
\hline 4. Leg (11.6\%) & 4. Shoulder (12.7\%) \\
\hline 5. Head (9.8\%) & 5. Hip (14.6\%) \\
\hline 6. Shoulder/Hip (6.7\%) & 6. Foot (5.5\%) \\
\hline 7. Neck (2.1\%) & 7. Neck, Hand, Elbow (3.6\%) \\
\hline
\end{tabular}

two healing fractures $\left(2^{\text {nd }}\right.$ metatarsal fracture $[\mathrm{NM}]$ and a patellar fracture [SPL], various tendinoses cases (posterior and anterior tibial, peroneal, achilles, and patellar tendinosis), two possible meniscal tears, two groin strains, and three hip contusions. Consistent with the medical history reports, no knee injuries occurred in junior or novice women events, but knee injuries, likewise, did not occur in the senior male, senior dance male, and junior dance male and female events. The eleven axial skeletal injuries included two cervical spine strains, one rib contusion and eight low back pain presentations (which will be discussed later).

Table 4 shows the type of injuries by event. $34.7 \%$ of the injuries were tendinous, $20 \%$ were ligamentous, and $10.9 \%$ were muscular. Four skaters with clinical evidence of lower extremity tendinosis also had concomitant bony tenderness.

Contusions accounted for $10.9 \%$ of the injuries and lacerations (requiring stitches) accounted for $12.7 \%$. One athlete had been treated for a herniated lumbar disc related to skating approximately six weeks prior to the competition, and as previously mentioned, two skaters were competing with healing fractures which were symptomatic at the time of competition. Several athletes were spiked, one senior female pairs skater sustained a three inch laceration to the calf and a senior dance male sustained a small laceration in the buttock. Collectively, the senior skaters represented 35 of the $55(64 \%)$ total injuries compared with $12(21.8 \%)$ injuries to their junior division counterparts.

Table 5 compares the medical history reports to on-site injury evaluation. The leg, knee, and low back were within the top four areas injured on both forms. The ankle was reported to have the greatest number of injuries according to the skaters' medical evaluation report, and yet less than $2 \%$ of all on-site injuries were to the ankle in competition. These differences may reflect inaccuracies in reporting. For instance, skaters may have reported a posterior tibial tendinosis as an ankle injury while the on-site injury evaluation clinician would have reported it as a leg injury. The low back region accounted for roughly $15 \%$ of injury reports from both forms.

\section{Low Back Injuries}

A female senior pairs skater who suffered a lumbar compression fracture upon 
colliding with the boards is not included, as she was evaluated and returned home soon thereafter. A novice female who incurred a lumbosacral injury is also excluded as her medical evaluation form was not available at the time of data compilation. The average age of the six skaters examined was 17.3 with a range from 16 to 23 . All but one, a 16 year old novice male skater, of the injuries represented exacerbations of a pre-existing process (i.e., one that did not occur at the time of competition). Five of the skaters who suffered low back injuries were male (three in the senior men class) while the remaining three were females. One skater with a herniated disc admitted to intermittent aching when landing a triple jump and one episode of radicular pain when landing a flying sit spin.

Most of the skaters were unable to precisely identify the time of onset of their low back pain, except for a senior pairs female skater with a pre-existing L5,S1 spondylolisthesis. She noted a "pop" in her back followed by loss of motion and pain after initiating the take-off in a waltz jump (a jump which involves a forward take-off on an outside edge and a $180^{\circ}$ turn in the air before landing).

Curiously, all skaters with low back pain were observed on physical exam to have hyperlordosis, hip flexion contractures (as assessed by the Thomas Test), and an inability to reverse their lumbar lordosis on forward flexion. All but one of the skaters had restricted rotation of the hips, most notably with internal rotation. In fact, a novice male presented with the inability to turn his feet inward enough to properly execute some portions of his competition routines. No attempt was made to goniometrically or otherwise measure hip or spinal range of motion. Most of the hip flexion contractures were greater than 15 degrees by visual inspection (via the Thomas Test). Four of the athletes had a positive Fortin Finger Test (indicating pain immediately below and medial to the PSIS), as well as sacral sulcus palpatory pain suggesting symptomatic sacroiliac joints (7). The remaining two skaters (including the 21 year old senior male skater with an L4, 5 prolapsed disc and a lumbosacral facet syndrome, as well as the 23 year old female pairs skater who had a symptomatic L5,S1 spondylolisthesis) with low back pain presented with established diagnoses.

\section{DISCUSSION}

Most of the injuries observed were of the overuse type, examples being posterior tibial tendinosis, enthesitis and patellar stress syndrome. These findings coincide with those of Smith and Micheli (3), but contrast Brock and Striowski's findings (5) of slightly more acute injuries in their questionnaire. Ankle injuries accounted for the largest percentage of injuries on the medical history reports while knee injuries accounted for the highest percentage of injuries on-site. Leg injuries also accounted for a high percentage of injuries in both cases. The predominance of lower extremity injuries found in this study and others may be related to the propulsion and jump landing mechanics involving forceful eversion and excess pronation in the young skaters (8).

In considering a differential association between the type of skating and injury characteristics, the most impressive statistic is the fact that pairs skaters accounted for more injuries than the single skaters. This contrasts with the findings of Brown and McKeag (2) (based on a questionnaire of six male and five female pairs skaters) but supports the findings of Brock and Striowski (based on a questionnaire of 13 pairs and 29 singles skaters). The higher incidence of injuries, especially to the head and shoulder in pairs skaters, may be a result of the high-impact ballistic carries, lifts and throws. In fact, Brown and McKeag (2) noted that concussions accounted for $33 \%$ of all injuries to pairs skaters. The nature of head injuries in pairs skaters has not previously been described. There were no significant differences between the shoulder injuries in female and male pairs skaters. This may be because in many carries and lifts the female partner is often supporting a good percentage of her own weight.

The current study documented more female versus male pairs skater injuries, commensurate with the findings of other investigators $(2,6)$. Prima facie, the female pairs skater seems more vulnerable to injury (than her male counterpart) as
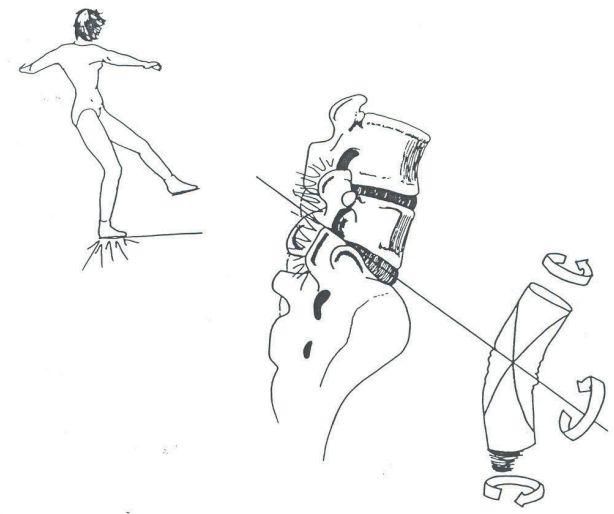

Fig. 1. a. Posterior view of skater landing a spinning jump. b. Posterior view of lumbosacral spine showing impacted facet joints. $c$. Forces concentrated at the neural arch as a result of moments introduced in the disc.

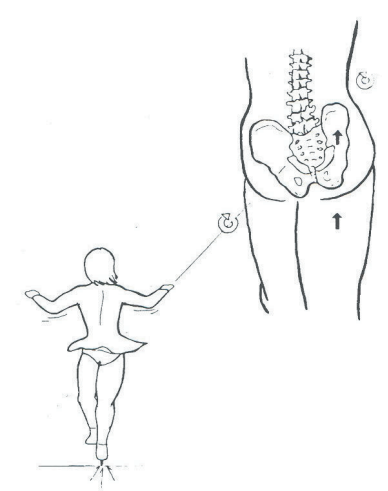

Fig. 2. Pelvic mechanics upon landing a spinning jump on ice. The axial load upon impact (straight arrows) places shear forces across the SI joint as the right innominate is displaced upward. The sacrum is concomitantly directed in a right facing torsion (curved arrows). 
she is tossed about the ice several times per routine by her much larger and stronger male partner. Our data also agrees with Brown and McKeag's observation (2) that single male skaters account for more injuries than single female skaters. The males' older age, greater body weight, and perhaps, the greater height, velocity, and impact of their jumps likely contribute to this disparity. Brock and Striowski (5) found eight of 14 acute injuries to be secondary to jumping. They related a lack of jumping activities and movements to fewer injuries incurred by the dance contingent. In that context, the present study, as well as the Smith and Ludington study, noted a lower incidence of dance versus pairs injuries.

Smith and Michell (3) disclosed low back findings similar to ours. Notably, there was a relationship between the skaters with tight lumbodorsal fascia, tight hip flexors and low back pain. Most of the young skaters with whom the authors have focused on preventing muscle imbalance, have never experienced low back pain. Several sports, such as weight lifting, gymnastics, and high jumping, requiring repetitive axial and torsional loading in a hyperextended posture, have been associated with an increased incidence of neural arch defects; suggesting such events subject the spine to great torsional stressors (9-12) (Fig. 1).

The role of propulsion, spin, lift and jump mechanics in the development of low back pain in skaters must also be considered. To this end, our findings, suggestive of SIJ pain (in several athletes) warrant particular mention. The wedgeshaped sacrum is jointed between the iliac bones by a complex self-locking mechanism. Repeated unilateral loads along the bicondylar axis of the femur to the innominate render the SIJ vulnerable to axial overload (i.e. sheer injury) (13-15). Repetitive jump landings on one extremity and missed landings that impact on an unbalanced buttock put a figure skater at risk for sacroiliac joint dysfunction (Figure 2). Since most landings occur on the right lower extremity, shear dysfunction most often affects the right sacroiliac joint and places the sacrum in a right-facing torsion. A functional short leg and ro- toscoliosis also may be part of the injury complex as Smith and Micheli documented a high incidence of scoliosis in the adolescent female skater (3).

\section{Conclusion}

It is difficult to compare our results with those of other studies, as the population and methods of data collection varied. We made no attempt to define the number of injuries per athlete hour, although we did note that all skaters received equal ice time. This creates difficulties when attempting to compare the relative role of injury in the figure skating population to that of other sports. It should be noted, however, that although skaters may not incur a high rate of injuries per hour (2), the very nature of the injuries observed suggests a relationship between the long hours of training and injury itself. As with many studies of this type, in a dynamic area which has not been extensively investigated in the past, more questions than answers have been raised.

Presently, we provide the following impressions:

1. The majority of injuries seen at this national event were re-exacerbations of a previous injury, suggesting a need to evaluate predisposing factors as well as methods of rehabilitation. Our conclusion is supported by the findings of Brock and Striowski (5) that overuse injuries accounted for greater periods of inactivity than acute ones.

2. Further studies are needed to determine how the effect of age, gender, type of skating and other variables influence patterns of injury.

3. The predominance of lower extremity injuries calls for investigation of bootwear materials (fit, alignment and stability) as well as a detailed biomechanical analysis of propulsion and jump landing mechanics.

4. The number of head injuries warrants a consideration of protective headgear and suspended harnessing devices when learning high risk maneuvers, particularly with the pairs skaters.

5. The nature of low back pain in this sport may indicate a relationship between injury and repetitive axial and torsional stressors, especially in a position of hyperextension.

\section{Author Affiliation: \\ Joseph D. Fortin, DO}

Medical Director

Spine Technology and Rehabilitation, PC Clinical Professor

Indiana University School of Medicine 7230 Engle Road, Suite 210

Fort Wayne, IN 46804

E-mail: fortin@pol.net

\section{Diana Roberts, PT, ATC}

Physical Therapist

Spine Technology and Rehabilitation, PC 7230 Engle Road, Suite 210

Fort Wayne, IN 46804

\section{REFERENCES}

1. Albright TE. Editorial comment, A/ Sports Med 1979; 7:46.

2. Brown PW, McKeag DB. Training, experience, and medical history of pairs skaters. Phys Sports Med 1987; 15:100-114.

3. Smith AD, Micheli LJ. Injuries in competitive figure skaters. Phys Sports Med 1982;10(1):36-47.

4. Smith AD. Foot and ankle injuries in figure skaters. Phys Sports Med 1990; 18(3):73-86.

5. Brock RM, Striowski CC. Injuries in elite figure skaters. Phys Sports Med 1986; 14:111-115.

6. Smith AD, Ludington R. Injuries in elite pair skaters and ice dancers. Am / Sports Med 1989; 17:482-488.

7. Fortin JD, Falco FJE. The Fortin finger test: an indicator of sacroiliac pain. Am J Orthop 1997; 26:477-480.

8. deBoer RW, Cabri J, Vaes W et al. Moments of force, power, and muscle coordination in speedskating. Int J Sports Med 1987; 8:371-378.

9. Adams MA, Hutton WC. The relevance of torsion to the mechanical derangement of the spine. Spine 1981; 6:241-248.

10. Farfan HF, Cossette J, Robertson $\mathrm{G}$ et al. The effects of torsion on the lumbar intervertebral joints: The role of torsion in the production of disc degeneration. I Bone Joint Surg 1970; 52(3):468-497.

11. Fortin JD, Falco FJE. The Biomechanical Principles of Preventing Weightlifting Injuries. Phys Med Rehabil State Art Rev 1997; 11:445-464.

12. Yang KH, King Al. Mechanism of facet load transmission as a hypothesis for low back pain. Spine 1984; 9:557-565.

13. Fortin JD, Falco FJE. Engimatic causes of spine pain in athletes. Phys Med Rehabil State Art Rev 1997;11:445-464.

14. Greenman PE. Innominate shear dysfunction in the sacroiliac syndrome. Man Med 1986; 2:114-121.

15. Miller JAA, Schultz AM, Anderson GBJ. Load displacement behavior of the sacroiliac joints. J Orthop Res 1987;5:92-101. 